\title{
Stability of Spiral Welded Tubes in Quay Walls
}

\author{
A.M. (Nol) Gresnigt; S.H.J. (Sjors) van Es \\ Delft University of Technology, The Netherlands \\ a.m.gresnigt@tudelft.nl; s.h.j.vanes@tudelft.nl
}

\begin{abstract}
A European research project (RFCS) has started to provide economic and safe guidance for the design of spirally welded tubes in combined walls. The main motivation for this project called COMBITUBE is that the current Eurocode 3 regulations for tubes in quay walls lead to uneconomic designs, because of poor local buckling design rules for these tubes. Because the most important load in quay walls is bending due to earth load, economic design implies a high diameter to wall thickness ratio. For relatively thin walled shells, the Eurocode 3 rules provide good results for the local buckling stress. For thicker walled shells where local buckling occurs when a part of the cross section has yielded, rather poor and uneconomic estimates of the local buckling bending moment are obtained. Also, no information on the deformation capacity is given. A solution for this problem is the application of strain based design methods, where the strain at local buckling is determined, from which the curvature (deformation capacity) and via the stress strain relationship, the bending moment can be obtained. The advantages of strain based design are explained. In comparison with longitudinally welded tubes and seamless tubes not much bending test results are available for spirally welded tubes. Therefore in the project full scale four point bending tests on spirally welded tubes with diameters up to $1060 \mathrm{~mm}$ are performed. Test results obtained so far are presented. The test results are used for the validation of FEA models for parameter studies where the effect of geometrical conditions (spiral welds and girth welds, geometrical imperfections), material properties and loading (mainly combinations of bending moment, normal force and earth loads) on the local buckling curvature and bending moment capacity are determined. Therefore, in the test program accurate measurements are performed of these conditions. Moment - curvature and curvature ovalisation relationships are presented and compared with theoretical predictions.
\end{abstract}

\section{Introduction}

Eurocode 3 Part 5 (EN 1993-5, 2006) covers design rules for combined walls, which consist of a combination of tubes and sheet piling (Figure 1) to be applied in e.g. quay walls. For the verification of the failure mode local buckling, EN 1993-5 refers to EN 1993-1-6, Strength and Stability of Shell Structures (2007). Application of these standards shows that this verification for local buckling may lead to very uneconomical designs. The main cause is the local stress buckling criterion in EN 1993-1-6, which is very restrictive for tubes where a substantial part of the cross section yields before buckling. The local stress buckling criterion is appropriate for thin walled shell structures such as tanks and silos, but not for thicker walled shells such as tubes for quay walls. The evaluation method in EN 1993-1-6 is stress based. For thicker walled shells, the local stress buckling criterion taking into account 
influences that affect the local buckling strength (e.g. imperfections), gives a too large reduction of the design stress and the bending moment capacity. A much better evaluation of the strength is possible using strain based design methods, as in modern pipeline standards.

Apart from strength, strain based design also enables a much better insight into the deformation capacity and the robustness of a quay wall structure. A combined wall is a parallel system where a single buckled element does not necessarily lead to failure. In the safety evaluation of such a structure, knowledge of the post buckling strength is needed. The post buckling strength highly depends on the diameter to wall thickness ratio $(D / t)$ and the stiffness and strength of the soil in the inside of the tubes.

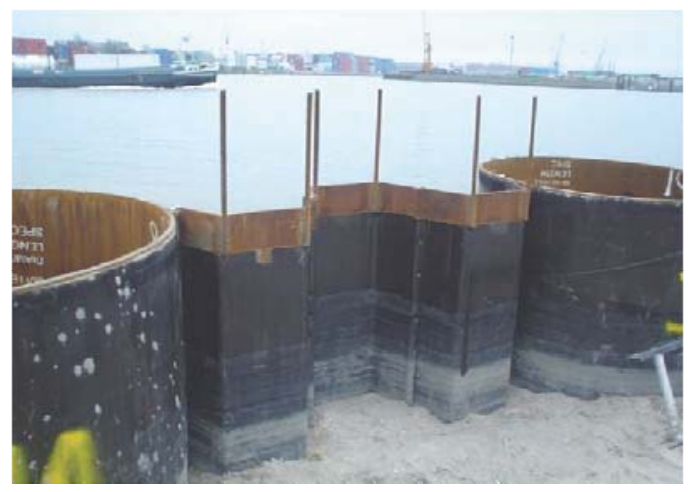

Figure 1: Example of a combined wall, consisting of tubular sections and intermediate sheet piling

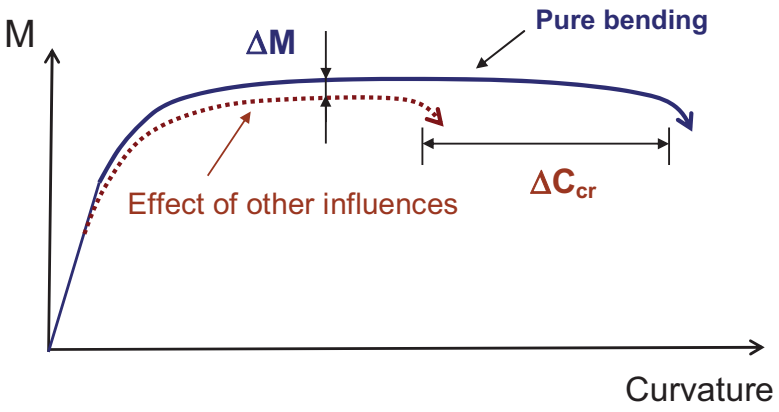

Figure 2: Effect of various influences on the bending moment - curvature behaviour

Strain-based design is believed to offer a promising method to harmonize different local buckling limits and to achieve a more balanced safety concept. Apart from the $D / t$ ratio, there are several other factors that have an influence on the local buckling behaviour and thereby on the bending moment capacity. Examples of such factors are:

- The stress-strain behaviour of the steel, in particular the strain hardening properties and the yield-to-ultimate strength ratio.

- Soil loads cause ovalisation and additional stresses and thereby influence the critical buckling strain and the bending moment capacity.

- External pressure decreases the critical buckling strain, whereas internal pressure increases the critical buckling strain.

- Support loads and load introduction points give local deformations and stresses and thereby de-crease the critical buckling strain.

- Initial imperfections such as ovality and dimples influence the critical buckling strain and the bending moment capacity.

The effect of these influences on the bending moment-curvature relationship is indicated in Figure 2.

In strain-based design the critical curvature is determined. The effect on the bending moment capacity $\Delta \mathrm{M}$ is often small and is easy to calculate. In stress-based design as in EN 1993-1-6 the effect of other influences is taken into account by reduction factors on the local buckling stress. This has a direct effect on the bending moment capacity, which may result in rather big decreases in bending moment capacity and over-conservative and uneconomic designs. 
Spiral welded tubes are produced from coiled steel. They can be produced in large diameters in any length and in a variety of $D / t$ ratios. Combined walls with spiral welded tubes have proven a safe and cost effective solution for many quay walls and building pits during more than 40-50 years, particularly in The Netherlands. The knowledge and experiences with strain based design for buried pipelines have been quit helpful (Gresnigt, 1986, 2010). In order to improve the relevant Eurocode standards and because not much research has been performed on the structural behaviour of large diameter spiral welded tubes in quay wall applications, a European research project has started, sponsored by the Research Fund for Coal and Steel (RFCS, 2011). The project consists of a combination of experimental testing, FEA parameter studies, analytical modelling and providing better guidance for design. In this paper the set-up of the experimental testing program in Delft is given as well as test results up till now.

\section{Testing Program}

The testing program consists of bending tests on spiral welded tubes with diameters 820 and 863 $\mathrm{mm}$ to be tested at the Karlsruhe Institute of Technology and $1067 \mathrm{~mm}$ to be tested in TU-Delft (RFCS, 2011). The tubes have $D / t$ ratios between about 70 and 120 . Steel grades are API X52, X60 and X70 with specified minimum yield strengths 358,414 and $483 \mathrm{~N} / \mathrm{mm}^{2}$. Special attention is given to the spiral weld, the girth weld and the coil weld: local shapes and imperfections such as high-lows, which can be much larger than usually in pipelines. For girth welds in combined walls no special clamps are used as for pipelines. Where in pipelines girth welds usually do not have much effect on the local buckling behaviour, girth welds in tubes for combined walls can have much larger high lows. The results of the testing program will be used to validate numerical FEA models and to aid further numerical parameters studies. Therefore it is necessary to measure in the tests accurately all parameters that are relevant for the FEA validations.

\section{Initial Dimensions, Material Properties and Geometrical Imperfections}

The program of measurements of the as-produced tube before loading consists of:

- Measurement of wall thickness

- Measurement of diameter

- Measurement of geometrical imperfections in the tube wall (in this paper called dimples)

- Measurement of material mechanical properties

- Residual stresses

While the first two measurements are mostly self-explanatory, the measurements of dimple imperfections require clarification. Of each tube, eight laser scans of a longitudinal line are performed over midsection of the tube that will be loaded during the test. Each scan takes place on a different section of the tube, by rotating it 45 degrees. The measurements are performed by a laser trolley driving on rails below the tube. An overview of the test setup is depicted in Figure 3.

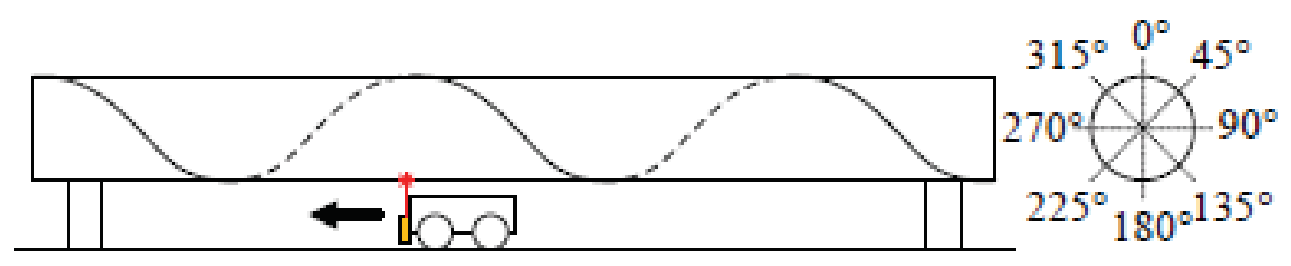

Figure 3: Schematic overview of laser imperfection measurements; spirally welded tube with laser trolley (left) and eight possible tube orientations (right) 
A typical result of this measurement is shown in Figure 4. The line represents the outer surface of the tube wall. Above the line will be air, below the line will be steel. Note the presence of the spiral welds (sharp peaks at regular distances) and dimples. The amplitude of the geometrical imperfections is an order of magnitude larger than the wall thickness variation. The measured geometrical imperfections are thus the result of plate bending and not wall thickness variation. The dimples show a regular pattern caused by the rollers during bending of the plate into a tube.

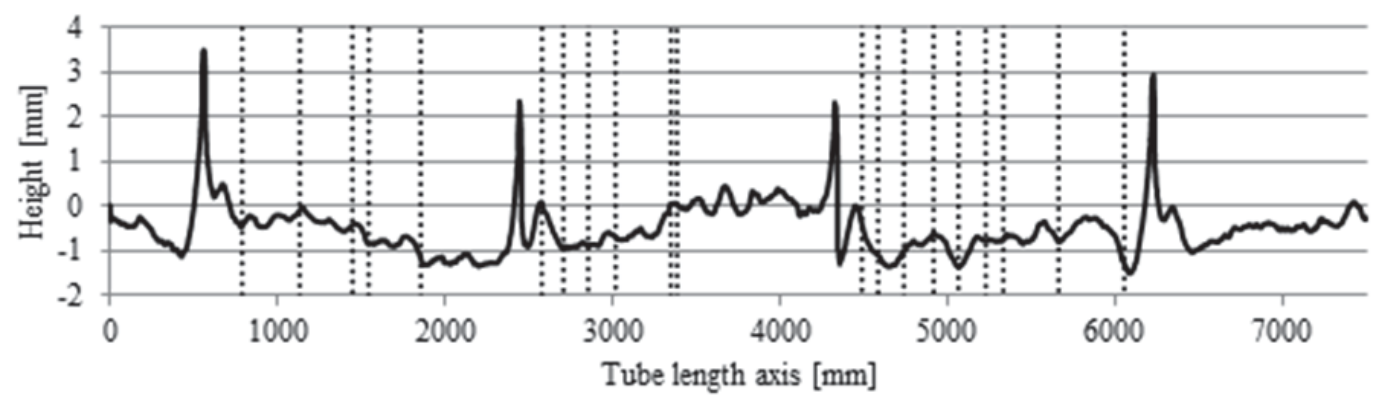

Figure 4: Laser scan of initial imperfections with overlay of visible roller marks for Tube T1 (1067x15.9 - X70), compression zone

Because the rolling direction of the material does not correspond with the main loading direction, material testing is executed also perpendicular and parallel to the spiral welds. An extensive measurement program was performed on the first tube 1067-16 mm, X70. The outside of the wall gave about $15 \%$ higher yield stress in circumferential direction and $9 \%$ higher yield stress in longitudinal direction. Also compression material testing is performed. Both tensile and compression test specimens showed a clear Lüders plateau with no Bauschinger effect as is usually seen at UOE pipe materials. An important factor of course is the smaller cold deformation.

\section{Test setup and measurements}

Because the tubes that are tested are full size, the forces and displacements that are involved in the test setup are of significant scale. The maximum pulling force at the ends is $3500 \mathrm{kN}$ with a maximum stroke of $350 \mathrm{~mm}$. An overview of the setup is shown in Figure 5 and Figure 6.

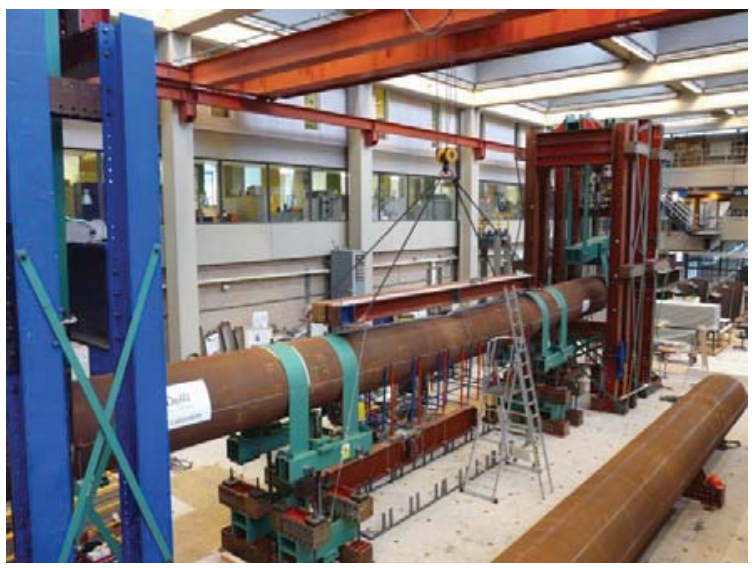

Figure 5: Four point bending test tube 'T3' $(1067 \times 9,0 \mathrm{~mm}$ grade $\mathrm{X60})$ with girth weld

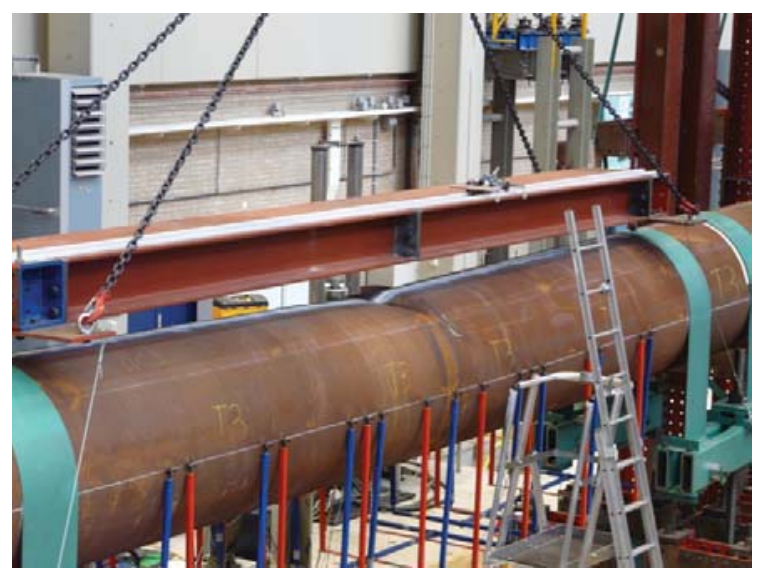

Figure 6: Local buckle at the girth weld 
The length of the central part between the straps is $6.35 \mathrm{~m}$. The thin straps provide a smooth load introduction, causing no additional ovalisation. The central straps are connected to the strong floor of the laboratory. During the test several continuous measurements are performed:

- Displacement both at the mid supports and end supports

- Applied force at the outer supports

- Ovalisation at regular distances in the area of constant moment (the blue frames)

- Strains at regular distances in the area of constant moment

- Curvature of the area of constant moment over three subsections (the red frames) and over the whole central length of the test tube.

Furthermore, at different load steps, a laser scan of the surface of the tube is made in a similar way as has been done to investigate the geometrical imperfections. The laser cart can be seen at the beam above the test tube in Figure 6. This measurement gives insight in the development of small wrinkles into local buckles during the increase of the curvature. Figure 7 shows a typical local buckle (diamond shape). The white line is because of the laser measurements. The central part is where the buckle starts, at some distance from the spiral weld. Inside the tube a laser on a cart on rails scans the cross sections at regular small distances. In Figure 8 a result of the laser scan from the inside of the tube is given.

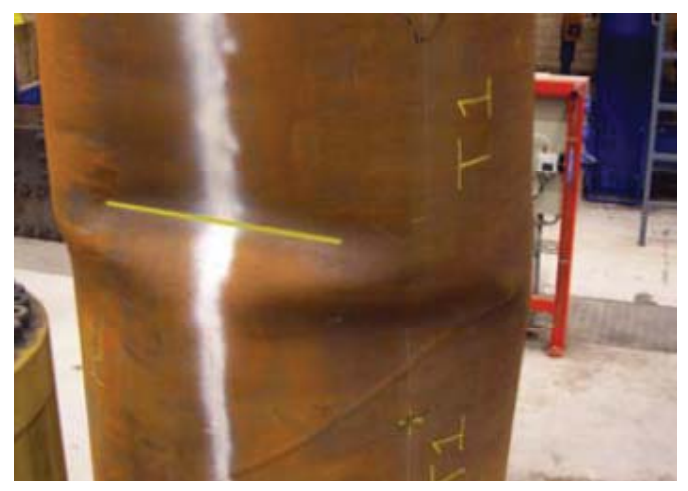

Figure 7: Local buckle test 'T1' (1067x16,0 $\mathrm{mm}, \mathrm{X70})$, no girth weld

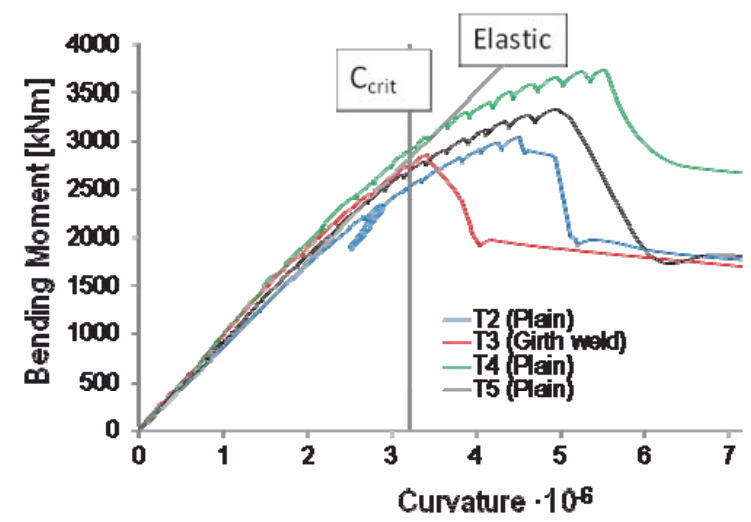

Figure 9: Moment - average curvature for tubes 'T2'-'T5' (1067x9,0 mm grade X60)

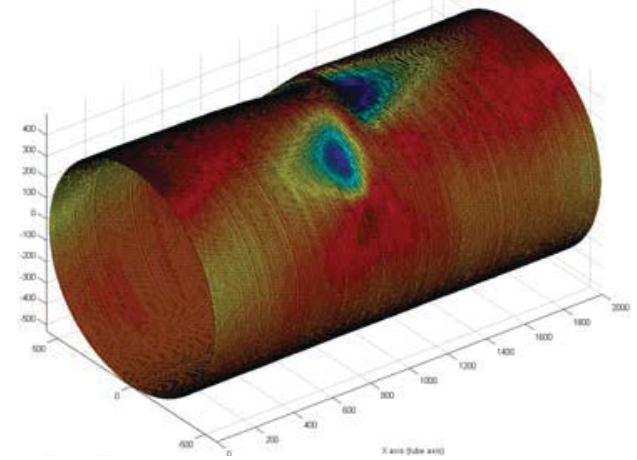

Figure 8: Laser scan with local buckle test 'T4' (1067x9,0 mm, X60), no girth weld

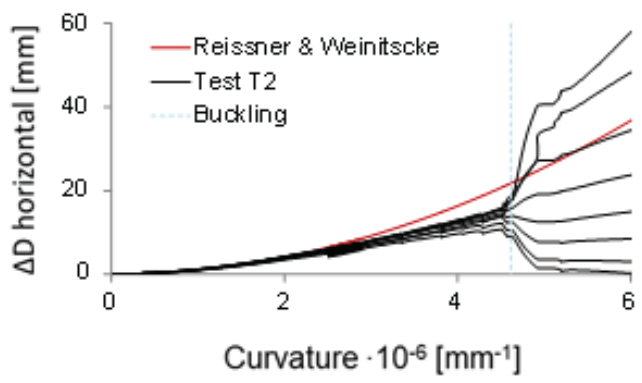

Figure 10: Ovalisation -curvature for test 'T2' (1067x9,0 mm grade X60) 
In Figure 9 bending moment-curvature diagrams are given. The critical strain $\varepsilon_{c r}$ form which the critical curvature $C_{c r i t}$ is calculated, is given below (Gresnigt,1986; ENV 1993-5,1998; EN 1594,2000). The effect of ovalisation, e.g. because of soil load is explained in Figure 11.

$$
\begin{aligned}
& \text { For } t / r^{\prime}<60: \quad \varepsilon_{c r}=0.25 \frac{t}{r^{\prime}}-0.0025 \\
& \text { For } t / r^{\prime} \geq 60: \quad \varepsilon_{c r}=0.10 \frac{t}{r^{\prime}}
\end{aligned}
$$

with:

$$
r^{\prime}=\frac{r}{1-\frac{3 a}{r}} \quad \text { and } \quad r=\frac{D-t}{2}
$$

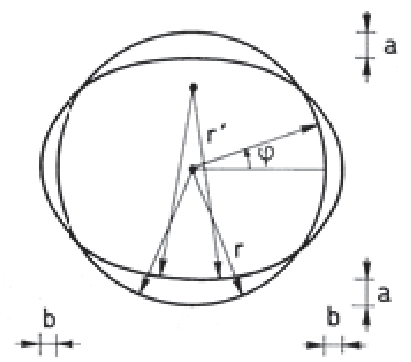

\section{Figure 11: Radius $r^{\prime}$ to be used in the design rules}

\section{Further Research within the Combitube Project, Acknowledgement}

In the RFCS project a similar testing program is executed at the Karlsruhe Institute of Technology. Numerical models are developed at the University of Thessaly and the University of Edinburgh. BAM Infra-consult in The Netherlands and ArcelorMittal collaborate within the project as representative of end-user and producer of the tubes. Calibrated numerical models will be developed to carry out parameters studies to formulate safe and economical design rules, suitable for implementation in Eurocode 3. We acknowledge the contributions from all partners and especially the European Research Fund for Coal and Steel for making the project possible.

\section{Conclusions}

Measurements of geometrical imperfections show a regular pattern of dimples due to the cold forming of the tubes with rollers during production. During the buckling tests, the tested tubes buckle at one of these, production related, dimples. Although at the spiral welds also geometrical imperfections are present, in the five tests so far they have not been the location of buckling. The test with a girth weld buckled at the girth weld. The results from the tests show good agreement with analytical models and FEA results (not in this paper). The project is still running and in due time more results (tests and FEA) will become available.

\section{References}

EN 1993-1-6 (2007), Eurocode 3: Design of steel structures - Part 1-6: Strength and Stability of Shell Structures.

EN 1993-5 (2008), Eurocode 3: Design of steel structures - Part 5: Piling.

ENV 1993-5 (1998). Eurocode 3: Design of steel structures. Part 5: Piling (withdrawn).

EN 1594 (2000). Gas supply systems: Pipelines - Maximum Operating Pressure over 16 bar.

Gresnigt, AM (1986). Plastic design of buried steel pipelines in settlement areas, HERON, Vol. 31, no. 4.

Gresnigt, AM, Jo, CH and Karamanos, SA (2011). Local buckling of tubular sections in structural applications. Proc. of the 2011World congress on advances in structural engineering and mechanics (ASEM'11plus), pp 1948-1967.

Reissner, E, Weinitschke, HJ (1963), Finite pure bending of circular cylindrical tubes, Quarterly of applied mathematics, Vol. 20.

RFCS (2011). Bending Resistance of Steel Tubes in CombiWalls, COMBITUBE. European Commission. 